\title{
Developing technology pushed breakthroughs: an empirical study
}

\author{
Jari Sarja ${ }^{1 *}$, Samuli Saukkonen ${ }^{1}$ Kari Liukkunen ${ }^{1}$ Elina Annanperä ${ }^{1}$
}

\begin{abstract}
Developing a technology push product that brings real novelty to the market is difficult, risky and costly. This case study analyzes success factors defined by the literature. True industrial cases, representing Finnish ICT firms in their early phase after a successful market entry, were researched for the success factor analysis. The whole set of the previously introduced success factors were variably supported, and three new factors arose. Because the technology pushed development processes are risky with high failure rates, the validated success factors are valuable knowledge for the developments intensive firm's management.
\end{abstract}

Keywords: New Product Development; Technology Push; ICT; Start-up.

Submitted: January $1^{\text {st }} 2017$ / Approved: November $22^{\text {nd }} 2017$

\section{Introduction}

Developing new and successful products is necessary for all development-intensive firms (e.g., Balachandra \& Friar, 1997; Cooper, 1994; Ernst, 2002). Because new product projects are risky and failure rates are high, it is obvious that the management of firms must be interested in those factors that lead to breakthrough innovations. In practice, success factors are defined to mean a limited number of elements or areas where "things must go right" for the business to flourish. These areas must be constantly and carefully monitored by the management, and they are necessary for an organization or project to achieve its goals (Rockart, 1979).

Previous literature on the New Product Development (NPD) discipline has presented conflicting findings regarding two key approaches, namely technology push (TP) and market pull (MP) (e.g., Herstatt \& Lettl, 2004; Samli \& Weber, 2000). The TP school swears that innovation is driven by internal or external research, while the MP school says that innovation is driven by the users' needs (Chau \& Tam, 2000). In past, most literature stresses that emphasis should be on MP (e.g., by Myers \& Marquis, 1969; Langrish et al., 1972; Rothwell et al., 1974; Utterback, 1974). Both concepts have their benefits and weaknesses. The market researched MP concept ensures, theoretically speaking, commercial success, but the products are incremental ones, ensured versions of current products, aka line extensions (Samli \& Weber, 2000). The TP concept does not guarantee a market demand, but the products have a high level of novelty. Currently, the literature encourages combining both approaches in NPD projects (e.g., Ulrich \& Eppinger, 2008).

Sarja $(2014,2015)$ has studied why some technology pushed ICT projects have succeeded. As an example, he mentions Apple's and Basecamp's products and Facebook. After a broad literature review (2015) including a few meta-analyses with almost 100 peer-reviewed papers and cases, he conducted a handful of success factors for closer examination. Because many of them were nebulous in nature, the explanatory definitions were given, and the survey instrument framework was defined. The framework compiled four different categories: market, product, management and organization [related] success factors. The theories behind the factors (e.g. Ansoff model, generic development process, alternative study), and the success factors are introduced in concept level in Sarja's research paper (2015b).

The aim of this study is to validate empirically the success factors of technology push products in the ICT industry. The goal of the validation is to find out the relevance of the introduced success factors and possibly define new ones. The validation is executed by an empirical study with semi-structured company interviews.

This paper proceeds as follows. At first, the research method and process are described. The following section provides the results of the empirical study. Here the authors address the validity of success factors in all four categories. We conclude by discussing the impact of success factors on future research and industrial NPD projects.

\section{Research approach}

We examined whether the TP success factors discussed above are relevant ones, whether any new factors have arisen during the exploration, and whether some of the factors are aimless. We also wanted to examine if some factors could be focused differently. We mapped our study as an exploratory and inductive case study. With this in mind, we chose the qualitative case study method. As a research method, the case study has been a common research method in many science disciplines. Yin (2009, p. 4) states that the case study method allows investigators to retain holistic and meaningful characteristics of reallife events, including organizational and managerial processes, such as in our study. In the case study method, the theory and data will be compared and iterated toward a theory that closely fits the data (Eisenhardt, 1989).

For evaluating discussed TP success factors we have followed Eisenhardt's (1989) widely cited theory building process (from case study research) where appropriate. In this way, we have sought to maximize the novelty, testability and empirical validity of the study.

(1) Department of Information Processing Science, University of Oulu, Pentti Kaiteran katu 1, FI-90570, Oulu, Finland.

${ }^{*}$ Corresponding author: jari.sarja@oulu.fi 
Also, the four tests of trustworthiness by Yin (2009, pp. 40) have been taken into consideration.

The data collection was conducted using semi-structured interviews (e.g. Myers \& Newman, 2007). The case selection was done intentionally (Runeson \& Höst, 2009) from theory building point of view instead of random sampling (Eisenhardt, 1989). The informants represent different sizes of Finnish ICT start-up firms with breakthrough products. Another common factor of interviewees is a long new product development (NPD) background either in their own business or as an employee. The number of cases was not planned at the starting phase, but the theoretical saturation (Glaser and Strauss, 1967) as well as minimization of the incremental improvement (Eisenhardt, 1989) of the study was reached. It was observable after the first few cases that the results of the interview were repeating themselves. In the end, the study was conducted with nine cases. Nine firms in the study were viable. It was supported well by the principle of Eisenhardt (1989): a number of cases between 4 and 10 usually works well.
The interviewees were typically founders of their own businesses, and the firms were typically established around a technology pushed product idea. Two interviewees were selected to leading positions due their experience, and they were also granted with a partnership. Half of the interviewees used a CEO title, and the rest of them were chosen for an expert task and given their title accordingly. The position of informant $\mathrm{G}$ is named as a "Founder" instead of his personal original title in order to protect his identity and linking to specific answers. The age distribution of interviewees was 28 to 56 years $($ mean $=42$ years, median $=46$ years). As mentioned before, most of them had long years of experience in NPD activities before starting to work on their own innovations. The entrepreneurship experience is mainly a suggestive variable because informants had different kinds of backgrounds: serial entrepreneurs, NPD experience as a worker, and entrepreneurial experience without NPD activities such as trading. Tables 1 and 2 describe the nine cases used in the study. The tables can be read in such a way that interviewee A represents company A, and so forth.

Table 1. Descriptions of the Informants.

\begin{tabular}{|c|c|c|c|c|c|}
\hline Interviewee & Position & Founder & Partner & NPD experience (years) & Entrepreneurship experience (years) \\
\hline A & $\mathrm{CEO}$ & $\mathrm{X}$ & & 16 & 3 \\
\hline $\mathrm{C}$ & $\mathrm{CEO}$ & $\mathrm{X}$ & & 1 & 10 \\
\hline $\mathrm{D}$ & $\mathrm{CEO}$ & $\mathrm{X}$ & & 17 & 3 \\
\hline G & Founder & $\mathrm{X}$ & & 16 & 12 \\
\hline $\mathrm{H}$ & СTO & $\mathrm{X}$ & & 28 & 3 \\
\hline I & CEO & $\mathrm{X}$ & & 6 & 3 \\
\hline
\end{tabular}

Five TP cases were hardware products, and four cases were software products. The business model in three cases was to sell to distributors and/or company users as well as straight to final users (A, C, I). It is noteworthy that regardless of the business model, in eight cases the final user could also be a private person. In other words, the product could be purchased by a distributor (A, C, I) or by a service provider (D, E, F, G, H). In one case, the product was only for business use and was sold straight to the business customer (B).

Table 2. Descriptions of the TP Products in Cases.

\begin{tabular}{llll}
\hline Company & HW/SW & B2C & B2B \\
\hline A & HW & X & X \\
B & HW & & X \\
C & HW & X & X \\
D & SW & & X \\
E & SW & & X \\
F & SW & & X \\
G & SW & & X \\
H & HW & X & X \\
I & HW & & \\
\hline
\end{tabular}

The 1.5 - 2 hour interviews were taped for transcription, and the content analysis method was used for analyzing the results. The interview questions were based on the study of Sarja (2014) who had a similar approach. We further defined the question list by adding more detailed background questions, and we also added one open question to the end of the list. The definitive question list is presented in Appendix 1.

\section{Results}

In this chapter, the TP success factors are discussed taking into account the case study results. Sarja $(2014,2015,2015 b)$ introduced $13 \mathrm{TP}$ success factors in four separate categories. These relatively theoretical success factors are based on extensive literature review and form the basis for the study. The success factors are introduced in Table 3 and in concept level in Sarja's research paper (2015b). 
Table 3. TP Key Factors.

\begin{tabular}{llll}
\hline Market related & Product related & Management related & Organization related \\
\hline MP methods used & TP for difficult adopted & Management support & Project team skills \\
Focus on customer needs & Life cycle & Degree of funding & Networking \\
Market development & Fill an unrecognized need & & \\
Alternative study & Technological advantages & & \\
Adoption time and technophobia & & & \\
\hline
\end{tabular}

\section{Market-related success factors}

MP methods used can be seen as an umbrella term for all market related success factors (Sarja, 2015b). In this study, the author defined two aspects of this factor: the development process and customer involvement. More precisely, customer involvement should be an early part of the development process (e.g. Ulrich \& Eppinger, 2008) regardless of the type of innovative new product (MP or TP).

Seven informants (out of nine, not mentioned in further text) stated they did not have any kind of defined and/or documented development process in the beginning. Two other informants said they used lean and agile methods (they did not specify the methods) at the beginning. Six informants stated that the defined development process had been put into operation or that process development was ongoing simultaneously with product development. Three informants did not see the formal development process as an important issue.

"We didn't have any defined development process. But we hired a guy who knew how the [developing] process should be implemented."

"No, we didn't have We just went ahead like a train and tackled issues as they existed."

"No we hadn't. A few years later we started to think processes when the number of employees was increased."

However, from a customer involvement point of view, the relations were contrary; six informants said they tried to find customers and introduced the product plan to the potential customers before or in the beginning of the development process. One informant had identified afterwards that this should have been done, and two of them stated that the customers found their product without any activities from their side. All nine informants stated they had made customers aware during the development process, in one way or another. The depth of cooperation varied from information sharing to gathering customer feedback and development ideas. One informant told about their learning process; they were serving the wrong customer, a retailer instead of the end user. All informants explained that the marketing aspect had been involved in the development process from the beginning.

"We started by trying to find customers. In fact, we established our business just because we found the lead customer."
"Yes. We started to sell our product in the beginning of xxxx (year) even though the product was not ready until the end of xxxx."

"Well, okay. The whole thing started by finding the customer need, and because I already knew some customers with that problem."

"We introduced our idea and then we refined that with the customer." "Yes. We have had a pilot customer for every product we have developed. My opinion is that you don't discover everything in the lab. There must be weight to different features. It looks different from the user's perspective."

"It was a one-man company at that time. I did everything by myself but marketing aspects were involved. I did not sell only products but rather benefits."

The factor focus on customer needs included two interests; customer segmentation and defining customer needs. Five informants said they had segmented customers clearly in the beginning of the development process. Three informants stated they did that partly, meaning that they noticed afterwards that the rigor of the study was not at the required level. Perhaps because of the general nature of the consumer product, one informant said they had not done any kind of customer segmentation.

"Yes, in the beginning we thought about what our target segment is.

Later on it turned topsy-turvy... it wasn't where we go now. Money talks, the market is where it comes."

Seven informants explained that they tried to clarify the exact customer needs in the beginning. Also, three of those were personally operating in a customer segment before establishing their own business. Two respondents explained they did that in a later phase or asked only about the desired features. All nine informants stated that the customer needs were documented in various forms and formalities: e-mails, sketch papers, back logs, use case documents, CRM (Customer Relationship Management) systems and reports. Five informants told that the customer needs documentation were also updated during the development process.

"Yes, we have written them as they come along. But it was not a process type operation. We were such a small team at that time, so the information was conveyed anyway. The tool has been case specific; email, CRM, or some other one." 
All nine informants mentioned they had analyzed and interpreted the customer need documentation. One result of the analyses had been typically a different kind of wish or feature which were mainly weighted and organized in order of importance. One informant said they did not reorganize based on the analysis because they had started to collect feedback too late and the product was already ready. In one case, the whole customer segment was omitted after the analysis due to the lack of resources. In some cases, the requested features were implemented without any further analysis, but in other cases, the customer required a solution that was too customer-specific. The weighting of customer needs occurred between asked-for features and the proposal of improvements, and in some cases, it was calculated according to the number of customer requirements.

"We have a very long wish list. We have to examine it very carefully and prioritize them and draw up a road map how to continue."

"We selected the most important use cases and they have to be in the next release. Any things outside use case list don't proceed."

"There was not any extraordinary systematics, but clearly according to how many customers felt it was relevant. Does it bring any new market or is it just incremental development."

\section{"All our customers hoped for a $x x x x$-function, so we prioritized that} initiative higher."

"All implemented things are not coming as requests, but also as customer problems."

Market development, in the sense of a success factor, describes recognized firm growth strategy opportunities (Ansoff, 1957), and it must be developed, instructed or prepared concurrently with the product design (Bishop \& Magleby, 2004). However, according to current understanding, based on practical industrial experience and the interviews of this study, the focus of market development should be stressed in the beginning of the development process or even before that (instead of as a concurrent activity). In many cases, the interviewees said that the idea was sold to the customer in advance. As an outcome of this, the entrepreneurs received letters of intent, pre-orders and even money payments.

"We even got the letter of intent before we started the development work."

"We did some pre-sales. The first batch we will produce has already paid itself. During that 30 days period I told the world that this kind of device is coming to the market, 600 people ordered and paid it in advance."

"The whole beta series was sold via web store, and we realized that there is a demand."
Comparing the answers of the interviews to the traditional Ansoff mo$\mathrm{del}^{1}$, all informants had recognized the type of market they tried to reach. Six of them defined that the target market was new for them and three of them aimed at an existing market. It seems that the informants were carefully familiarized with the target market, and most of them were even divided segments to the smaller pieces. Markets were also divided geographically. In six cases, the target market had changed during the development process and updates had been made accordingly.

"We build a kind of internal 'segmenting automat'. It happened via our price setting. 5\% of our customers are too big for us, and $25 \%$ are too small and they are not able to pay our monthly charge."

At the beginning of the product development process, alternative $s t u d y$ is a sub-process similar to customer need identification (Sarja, 2015b). The focus of the alternative study is to not only recognize product types created by competitors but also to create an alternative solution for addressing customer needs (Lewitt, 1960; Peteraf \& Bergen, 2003). In this study, the competitor field was deeply examined. All informants explained they had studied alternative solutions in terms of products in the market and in terms of customer needs to be served. In other words, they had mapped direct competitors and their products as well as indirect competitors serving the same customer field and at least partly solving the same problems.

"Yes, we studied all competitors' solutions. We even became acquainted with our customers' old devices."

"Because of our previous experiences our vision of alternative solutions was clear, we knew them precisely and we knew what was still missing in the market."

"Naturally we have studied these alternative solutions... and did they destroy our product idea? But we concluded that never in this life."

Five informants said the alternative study was updated during the product development process, and the rest states there had not been a need for that because the existing solutions had not changed. The document forms of the study varied in the same way as customer needs identification.

Adoption time means a time period when the customer adopts new products or ideas. The more novel a new product is, the longer the adoption time (e.g. Samli \& Weber, 2000). The concept of technophobia is a combination of technology-based new product anxiety and negative attitude. Research communities emphasize a commercial motivation for continued user-friendliness in hardware and software solutions for reducing adoption time and technophobia (Brosnan, 1998; Davis, 1989). Different technology acceptance models are developed for supporting that. The simplified message of acceptance models is that the user must feel that an application is useful (perceived usefulness) and easy to use (perceived ease of use) (Sarja, 2015b).

(1) Ansoff model is a commonly used product-market growth strategy. It is thoroughly presented e.g. by Ansoff (1957) and Pleshko \& Heiens (2008), and the applicable part summarized by Sarja (2015b). 
In our study, we examined whether the case firms considered the adoption time during the development process. Two informants told they did not consider the adoption time at all. Interestingly, both of those case firms were one-man companies at the time their products came to market. Another similarity was that in both cases, the market entry was smooth and did not require much special effort. The rest of the seven informants were able to explain their actions for reducing adoption time. Two of those informants stated that they did not think about adoption time in advance or during development time, but instead they learned about adoption time after market entry. Typical functions that informants listed for reducing customers' adoption time were advertising, sample distributions, trade fair introductions, customer involvement in the development process, communication, development of delivery and sales processes, ease of use, customer training, pre-sales and helping customer to simplify their processes. The data also included a few comments about failed actions.

"It didn't cause any changes to the final user. The storekeepers got a new model of the application. From that point of view the storekeepers knew what they got from us, regardless of the new package. That's why their adoption time was very short."

"We have learned this a bit hard way. The big part of our product should be the launch and implementation. Actually, this is the most center stage of our job just now."

"We have sent samples to wholesalers and distributors. But unfortunately it doesn't increase the end-users' awareness."

The ease of use was an important premise in all cases. All nine informants confirmed that they were aware of the ease of use, and it was perceived during the development process. A typical target for the case firms was that the final user be able to use the product without a manual. The ease of use was measured in different ways in the cases: with customer feedback, automated integrations and minimalist designs. In one case, the product was relatively complicated, and in that case, the firm established an Internet-based learning environment with video instructions. The perceived usefulness was also an important premise for most of the cases. Eight informants gave examples of how usefulness was taken into consideration during the development phase. Typically, the information was collected straight from the customers and/or end users.

"We have invested lots to ease of use. We have hired a user interface designer to our development team."

"That [the ease of use] was a starting point. The user focus to his (or her) core action to the full, and the technology is only helping him (or her). As a result we designed a one button user interface, and all technology is hidden behind that."

"This doesn't differ from a normal device in any way. All its features are built-in. All users can use this spontaneously."

\section{Product-related success factors}

We discussed above adoption time and shortening it from the customer behavior point of view. The success factor TP for difficult to adopt considered the developers' perspective: how to commit and survive during the adoption time when the new product does not bring a cash flow to the firm (Sarja, 2015b). This is an essential question for startup firms, which are established around one innovation and without a cash flow generated from other products.

Six informants explained the different actions they executed for surviving during adoption time, one informant said they realized the adoption time in practice and learned what they should have done, and two informants explained that their business customers were involved with the project so deeply that the adoption time was funded by the customer. Typical ways for funding adoption time were economic planning, use savings, applying external funding and also expanding the ownership base. Furthermore, many activities of customer involvement discussed in the last chapter (2.1) were brought up again, for example pre-sales.

"In the very early phase we planned how to survive from the Death Valley. The main way was to connect the customer deeply to the development process."

"Design, marketing and sales have been involved in the developing process from the beginning."

All nine informants emphasized their management's commitment to the development project. The answers were similar because in all cases the management consisted of entrepreneurs. The commitment was inclusive because all projects had been established around the management's own product idea, and the start-ups were funded with the management's own money. In addition, two of the case firms were one-man companies in the beginning. The tricks for committing to the projects were working long days, working without salaries, or receiving salary income from other work. The adequacy of resources was ensured by financial arrangements and resource allocation. Two informants explained personnel transition inside the firm when they were transferred from the development process to customer deliveries. One informant described the resource allocation between two firms owned by the same owners. The main themes, from developing firm point of view, for surviving the adoption time period seemed to be the appropriate proportion of resources and bootstrapping funding.

"Because the management is the same as owners, and their own property is pledged... that guarantees the commitment"

"Our resources have been limited, so the schedules have been flexible. We have funded our work in different ways. Mostly we have gotten our salary elsewhere."

"This is a big challenge for us. Same resources work with product development and product deliveries. When we concentrate on the other one, the other one gets less attention." 
"That's why we have those priority lists. They tell the order of the development processes. From the staff's point of view we started development weighted, and now the weight is moving to sales activities."

A firm's target for developing new products is to get long-term profits (e.g. Griffin \& Hauser, 1996). When asked about the life cycle, all nine informants were able to tell at least something about the life cycle of their products. The most cursory comments were about expected life time estimations, and the most advanced ones were about the real life cycle planning already in the development phase. The expected life cycles were from one year to endless (SW products with continuous releases), and the depth of the life cycle planning was performed accordingly.

"It's a managements' task to make sure, that when the new version is released, the customers can upgrade. In other words, the product development keeps an upgrade, or in a sense life cycle in a delivery process."

"We see that this product is endless. New versions will be released monthly."

"This is a device which must be maintained and repaired. And its working environment is very challenging. We couldn't take this into account beforehand. But we learned that by trial and error."

"We thought about upgradability. The device can be upgraded almost similar to the latest version just by changing some 'bricks'. This was a part of our life cycle planning."

"One thing was that we designed the architecture of the device to be modular. We are not dependent on any technology, and the subparts are changeable."

Six informants stated that they had made economic plans for the product's life cycle period. Two informants explained that they were doing regular economic plans but not necessarily from the life cycle viewpoint. Instead, they mentioned economic planning as part of their firm's common activity and funding applications. One informant explained they do not do economic planning as a process but still try to optimize the costs.

In five cases, human resources planning for the life cycle period was carried out, and in three cases that was irrelevant because of the small size of the firm or the fact that the development work was outsourced. In one case, the planning was done only in the management's mind and not as a formal process.

"Yes, we did economic planning. We are a SaaS company and the biggest item of expenditure is product development and maintaining."

"No we haven't planned. But still we have tried to optimize the costs. Not necessarily by minimizing, but if something cost more and was an easier solution, we preferred that one. We always chose the easiest option."

"Yes, we do [human resources planning] as a part of head count and task allocation."
The success factor fill an unrecognized needs is ignored in this study, and we propose to remove it from the TP success factor set. Samli \& Weber (2000) state that the market and the customer needs must be studied by the developers. This is discussed deeply in the 'Market related success factors' chapter.

The factor technological advantages was sorted out by asking about the technological ability and availability of the development project and by asking how the developed products differed from competing solutions technology-wise. The most common sub-factor was the technical know-how and ability of the development team. In some cases, it was due to the long experience of the developers, but in some cases a shorter amount of experience with enthusiasm led to the same ability level. Apart from that, the ability to combine existing technologies in new ways was mentioned in a few cases. The other repeated issues were successful technology choices and particular ability in some sub-process (e.g. manufacturing cost reduction). Technological advantages in developed products offered many benefits to the customers (e.g. smaller size, simplicity, safety, connectivity [with other platforms and devices], reliability, possibility to use in new environment, feature extensions). From the developers' perspective, technological advantages enabled cheaper and more robust product development and production.

"We have combined existing technologies in a way that no one had done before. In the customers' eyes it's totally new technology."

"The core competence of this kind of firm is technology know-how. It is a prerequisite for the whole operation."

"Our audio and mechanical abilities are on the top of the world. We also have some simulation methods which others don't have, yet."

"We have benchmarked the best solutions from competitors, but we have benchmarked also from other industries using the same technologies."

"We are able to use technology which enables fast and cheap product development, and thereby the competitive price to the customer."

\section{Management-related success factors}

In this study, management support, as a success factor, is limited only for resource organizing (like Samli \& Weber, 2000; Ernst, 2002). This success factor does not sit very well with the start-up firms wherein the management are also the principal owners and the business is built around one product innovation. However, the informants were able to tell about a few issues related to management support. Surprisingly,-maybe because of the Finnish economic situation-they saw the most important support from management was ensuring the continuity of the project, in other words, employment. In start-up cases with always limited resources, most of informants also saw time as a resource and as a solution for limitations of the other resources. Interestingly, when asked about the adequacy of resources in the development phase, all informants declared they would prefer to have more resources, but in the end, they found that they had enough 
because they were able to complete the product. Also, the know-how, information sharing, strategic guiding and activity focusing were mentioned as management support tasks.

"Know-how, resource organizing and the fact that it's possible to tell at least somewhat that there is a future in this business. For sure we have had exciting times but the management can't show it outwards."

"In our case, it has allowed to work in peace. I think the workers have appreciated it. The whole story has been the continuity."

"The whole start-up bustle is about scarcities."

"In start-up firms this all is always a challenge. With more resources we would be able to develop more and faster."

"With more resources the workload would be tolerable. But it seems that performing sensibly it's possible to go forward with a smaller head count."

Samli \& Weber (2000) and Ulrich \& Eppinger (2008) outlined that adequate funding must be available and maintained during the development process for carrying it out. This degree of funding must be ensured by aggregate planning and prioritizing for the projects that are realizable within the budgeted resources. Also, this success factor did not sit well with start-up firms with only one product. However, similar prioritizing with mentioned one arose, but the target of prioritizing was product features. All nine informants stated they either had an R\&D budget, or they just used the biggest part or all available money for development work. All informants agreed the importance of prioritization. In five cases, prioritization was about the product features, and in one case, prioritization was done between the development of the application and the development of the supplementary services. In the rest of the cases, it was explained that prioritization was around the one and only existing product. In all cases, project funding was monitored at different levels and by different measures. The most common measures were monitoring budget realization and cash flow.

"In this case we used $100 \%$ for this project because we didn't have any other projects."

"Yes, it [the budgeted money] is pretty much gone from hand to mouth."

"We have only one product. We have prioritized its' features."

"Yes, we thought business first. We organized features according to how we got more business."

"The budget monitoring has been very easy. We have had planned money for molds, marketing and salaries. And it has all gone. In the beginning the budget was very precise and then we used that money."

"In principal, we have been doing financial calculations all the time, and also monitored the cash flow."

\section{Organisation-related success factors}

Following the idea of Sarja (2015b), we did not considered project team skills at the individual level, instead we focused on the versatility of cross-functional teams. All interviewees described their project teams as very experienced time-wise. One younger informant described his experience in a relatively modest way, but after reasoning, we concluded that he was very experienced with the new technology used in his project, also on a global scale. In three cases, the entire project team was described as very experienced, and in five cases, the founders were highly experienced but later they also hired younger avid employees.

"We have very experienced system designers and then we have hired younger to learn, and they can come straight from school. I see that we have a large scale of experience."

"In firm's starting phase we had a very experienced gang, everyone understood what was going on. Later we have hired also younger workers. We have a good mix of older experienced guys and younger dudes with fresh thoughts. In recruiting-wise we are always looking for the type."

When discussing the versatility of the development teams, two interviewees stated their teams were purely engineer-driven, and two other cases, which had started as a one-man project (in a starting phase), were also engineer-driven. One of these one-man cases extended its know-how by hiring and the other one by outsourcing the whole development work. The rest of the cases had been crossfunctionalized since the beginning. The typical cross-functional team in these small case firms consisted of engineering and commercial backgrounds. Both of these fields of know-how are divided for more exact expertise (e.g. user interface expertise, coding, testing, database expertise, marketing, sales, customer service etc.). In many cases, the know-how outside these mentioned fields was outsourced.

"Yeah, we have room for improvement in this engineer-economist driver [of the organization] now when we have grown bigger. So far we have utilized subcontracting in this."

"Our team members have different backgrounds. Commercial, technical, financial, marketing. We have people of different types even inside the unrelated teams. The common factor is passion."

"Versatility is a mental issue! All you need is the desire to learn and do!"

"It has been very important from the beginning that the wholeness was well planned. So that we would be able to start to sell as early as possible. Marketing, image, design, media expertise, all this was planned since the beginning. R\&D is only part of it! We have gotten positive feedback because of this [from the investors and consultants]."

The case firms arranged various different kinds of team training. Three interviewees stated that training was not arranged at all or had been internal or self-study. Four interviewees said they had conduc- 
ted unplanned training sessions when needed (e.g. when some new tools were introduced). In two cases, team training had been planned as part of the operation, and it was arranged regularly.

In conclusion, it was clear that the entrepreneurs saw employees as a vital resource, and they invested in recruiting. All nine informants said that they had a fully committed and capable development team. In most of the cases, the development team had also been very professional. In two cases, the possible lack of expertise was replaced by enthusiasm with good attitudes and self-study.

Networking is a traditional and widely studied success factor in the NPD discipline, and in the process of time, new interest groups are connected to the network (see Sarja, 2015b). The main purpose of networking is to consolidate in-house know-how and resourcing beyond the development teams. It is particularly important for TP development intensive firms (Ledwith \& Coughlan, 2005) and small resourced startups. Ledwith \& Coughlan (2005) have defined a framework ${ }^{2}$ for managing firms' networking which we followed in this study.

All nine informants explained that they had done networking, but the level of these activities varied. In all cases, informants mentioned different Finnish public sector players as a network partner because of funding and other public support activities. In two cases, the collaboration was mostly with the manufacturing partner $\left(\mathrm{EMS}^{3}\right)$, but both cases were active and open regarding new collaboration. In one case, the whole operations model was based on networking; public and privately funded firms was operated by one person, and the development and design work was outsourced. The rest of the six cases were operating somewhere in the middle ground.

In addition to the previously mentioned activities, collaboration with software platform distribution firms, marketing firms and joint marketing, open source communities, and research institutes and academies was mentioned. The noteworthy networking activities were product development in collaboration with the customers and complementary development work with competitors.

A needed and available know-how was the most important driver for the firms' networking, and such know-how was mentioned in every case. In the cases of EMS, academia and research collaboration the geographical closeness saw to play some role but otherwise the networking happened at national and international levels. In three cases, the key persons in the firms had ready contacts and networks from previous positions, and in two cases, the national research programs were mentioned as a tool for networking.

"We needed knowledge, skills and competence to make things happen. We didn't want to invent the wheel again."
"It was relatively need driven [action]. We needed something that was what these particular players were able to supply. The networking happened in the national level."

"That [national research program] was our proper networking action during the development process. From that way we got also contacts with the research institutes."

"Then, we have discussed with the other players of the industry and thought how to combine our businesses."

"I would allege that we have made a big difference in it. Before everyone who did somewhat similar things was a competitor and no one didn't discuss or do anything with them. Now we [can cooperate] and avoid overlapping and inventing the wheel again."

\section{Proposed success factors by an empirical study}

The last question of the interview (see Appendix 1) was open, and its purpose was to clarify how well the 12 (the factor fill an unrecognized need was excluded during the study) defined success factors covered the operations of the case firms in real life, and if the informants were able to define some additional success factors based on their experience of developing TP product for the market.

The coverage of the introduced success factors was supported in two ways. First, all informants were able to respond to all questions and discuss all factors. Secondly, all responses to the open question started by repeating already discussed factors instead of defining new ones. After the interviewers redirected conversation, the discussion turned to new proposed factors.

Most of the proposed success factors were just a case-specific ideas suggested by one informant only. However, three generalized thoughts arose from more informants, namely scalability, visibility and timing.

Half of the interviewees brought up the characteristic of scalability. Two of them explained that the scalability of the product is necessary in the consumer product group. The scalability must be noted already in the product planning phase.

"We planned the architecture so that the final product is scalable."

"If you do what the customer wants you can create a consulting business, not a scalable product like this."

"If you do exactly what the customer wants you likely to end up doing customer projects. You need to have a scalable solution which can solve the problem of many customers."

(2) The authors have found conflicting findings in studies between networking on a NPD and increased success. The framework represents the best understanding about the firms' successful network management, and further research is needed (see Ledwith \& Coughlan, 2005 and Sarja 2015b). A simplified description about the framework is questions with who, why, and what skills the collaborating organizations have.

(3) Electronic Manufacturing Services 
Three informants saw visibility as an important success factor in their cases. In all of these cases, the entrepreneurs started to publicize their product already during the development phase (as soon as IPR issues were ensured) and pre-sell successfully. Two interviewees were able to create a kind of phenomenon by way of good visibility. It was also noted that visibility was a great advantage in funding negotiations.

"The visibility has to be good! Must be in the press. The whole pipeline from the product development to the media service must be planned."

\section{"It is always positive if you can create a phenomenon. It boosts the} grapevine [and awareness of the product]."

"The visibility in web and media has greatly helped this exercise. The visibility in the media and getting into viral phenomenon. Personification, and building a community around the phenomenon or person."

In five cases, successful timing for market entry was seen as a success factor. In this context, timing was seen from a technology and product maturity point of view. The technology in use should be ready enough for commercial solutions, but the rough version of the product is enough for market entry. Three informants explained that the first version of their product on the market was a rough one, and the next versions were upgraded. One informant explained that he started to sell a product that did not even exist. The optimized timing for market entry seemed to increase the visibility of the product and funding of the development work.

"The used technology must be mature enough. It influences also the length of the adoption time."

"We were in the right place at the right time! We got our product to market fast. We started to sell it when it was still rough, and then fixed it."

"We think that the market entry should be done early enough. No need to do things too ready, in every case it will never be ready. We must recognize that the product isn't too rough but it's workable. You can do certain things with that but it's not perfect."

\section{Summary of the empirical study}

As mentioned, all 12 success factors were supported by the informants, and three more factors arose during the study. The factors fill an unrecognized needs were removed. We positioned the new success factor scalability in the product-related success factor group because it was clearly a planned characteristic of a developed product. Visibility and timing were strategic management decisions and naturally management-related factors. The whole set of empirically validated TP success factors are presented in Table 4.

Table 4. TP Key Factors after the Study.

\begin{tabular}{llll}
\hline Market- related & Product- related & Management- related & Organization- related \\
\hline MP methods used & TP for difficult adopted & Management support & Project team skills \\
Focus on customer needs & Life cycle & Degree of funding & Networking \\
Market development & Technological advantages & Visibility & Timing \\
Alternative study & Scalability & & \\
Adoption time and technophobia & &
\end{tabular}

\section{Conclusion}

In general, we can conclude that this empirical study supports that the discussed $12 \mathrm{TP}$ success factors are relevant. It also raised three new factors. We saw that the age of the informants or the years of the entrepreneurial or NPD experience did not played any role because of the small sampling and the nature of the case study method, but it was rather interesting background information. However, the amount of experience came up from time to time, and of course it can have a positive effect on a firm's performance.

It is not possible to put success factors in order of importance with this level of information, but it can be concluded that the weight is in marketing-related success factors. A large number of factors belong to that group, and perhaps it is the most researched discipline.
It is notable that the achieved results are generally level. We studied the whole set of success factors empirically knowing that every single case or every single success factor would be an adequate target for its own study. That way it would be possible to receive more detailed knowledge about each factor's function, efficiency and application of the factor as a part of firms' development processes.

During the research process, we also noticed three variables that should be taken into account in more elaborated studies: the product type (HW/SW), the business model (B2C, B2B) and the size of the studied case firm. In many (but not all) cases, the responses were similar between hardware firms and also between software firms. The same occurrence recurred between firms with the same business model and firms representing the same size. We propose that in future research at least these three characteristics should be distinguished. As discussed, the common factor of our case firms was that they are 
all start-ups that had already placed their product on the market. Still they represent different sizes in human resources (e.g. head count, turnover). Some success factors do not sit very well with the small firms that have only one product and where the management are also owners. For example, the questions regarding management-related success factors would apply better to bigger and older players in market with thousands of employees and several products rather than to start-ups.

As discussed, future research should go deeper by studying a limited number of success factors (even only one) within several cases. Another fruitful approach could be to focus only on cases of one product type, similar business models or firms of the same sizes. In addition, it might be beneficial to compare the implemented success factors and the success of the company's prosperity.

\section{Acknowledgement}

This work was supported by TEKES (Finnish Funding Agency for Technology and Innovation) as part of SoHealth research project and HILLA research program.

\section{References}

Ansoff, H.I. (1957). Strategies for diversification. Harvard Business Review, 30, 113-124.

Balachandra R. \& Friar J. (1997). Factors for success in R\&D projects and new product innovation: A contextual framework. IEEE Transactions on Engineering Management, 44(3), 276-287.

Bishop, G.L. \& Magleby, S.P. (2004). A review of technology push product development models and processes. Proceedings of ASME DECT '04. ASME, New York, NY, 383-392.

Brosnan, M. (1998). Technophobia: The psychological Impact of Information technology. Routledge, NY.

Chau, P.Y.K. \& Tam, K.Y. (2000). Organizational adoption of open systems: A 'technology-push, need-pull' perspective. Information \& Management, 37, 229-239.

Cooper, R.G. (1994). New products: The factors that drive success. International Marketing Review, 11(1), 60-76.

Davis, F. (1989). Perceived usefulness, perceived ease of use, and user acceptance of information technology. MIS Quarterly, 13(3), 319-340. Eisenhardt, K. N. (1989). Building theories from case study research. Academy of Management Review, 14(4), 532-550.

Ernst, H. (2002). Success factors of new product development: A review of the empirical literature. International Journal of Management Reviews, 4(1), 1-40.

Glaser, B. \& Strauss, A. (1967). The discovery of grounded theory: strategies of qualitative research. London: Wiedenfeld and Nicholson.
Griffin, A. \& Hauser, J. (1996). Integrating R\&D and marketing: A review and analysis of the literature. Journal of Product Innovation Management, 13(3), 191-215.

Herstatt, C. \& Lettl, C. (2004). Management of 'technology push' development projects. International Journal of Technology Management, 27(2-3), 155-175.

Langrish, J., Gibbons, M., Evans, W.G. \& Jevons, F.R. (1972). Wealth of knowledge. John Wiley \& Sons, New York.

Ledwith, A. \& Coughlan, P. (2005). Splendid isolation: Does networking really increase new product success? Creativity and Innovation Management, 14(4), 366-373.

Lewitt, T. (1960). Marketing myopia. Harvard Business Review, 38(4), 45-56.

Myers, S. \& Marquis, D.G. (1969). Successful industrial innovation. Washington, DC: National Science Foundation.

Myers, M. D. \& Newman, M. (2007). The qualitative interviews in IS research: Examining the craft. Information and Organization, 17(2007), 2-26.

Peteraf, M. \& Bergen, M. (2003). Scanning dynamic competitive landscapes: A market-based and resource-based framework. Strategic Management Journal, 24, 1027-1041.

Pleshko, L.P. \& Heiens, R.A. (2008). The contemporary productmarket strategy grid and the link to market orientation and profitability. Journal of Targeting, Measurement and Analysis for Marketing, $16,108-114$.

Rockart, J. (1979). Chief executives define their own data needs. Harvard Business Review, 57(2), 81-93.

Rothwell, R., Freeman, C., Horsley, A., Jervis, V.T.P, Robertson, A.B. \&Townsend, J. (1974). SAPPHO updated - project SAPPHO phase II. Research Policy, 3(3), 258-291.

Runeson, P. \& Höst, M. (2009). Guidelines for conducting and reporting case study research in software engineering. Empirical Software Engineering, 14(2), 131-164.

Samli, A.C. \& Weber J.A.E. (2000). A theory of successful product breakthrough management: Learning from success. Journal of Product \& Brand Management, 9(1), 35-55.

Sarja. J. (2014). Success factors of breakthrough technology push projects in ICT context. Licentiate thesis. University of Oulu, Oulu, Finland.

Sarja, J. (2015). Key factors of successful technology push projects in the ICT context: a review of the literature. International Journal of Information Technology and Management. 14(4), 253-273. 
Sarja, J. (2015b). Explanatory Definitions of the Technology Push Success Factors. Journal of Technology Management \& Innovation, 10(1), 204-214.

Ulrich, K.T. \& Eppinger, S.D. (2008). Product Design and Development. Irwin/McGraw-Hill.
Utterback, J. (1974). Innovation in industry and the diffusion of technology. Science, 183(4125), 620-626.

Yin, R. (2009). Case study research: design and methods. Sage Publications. 


\section{Appendix 1. Interview question list}

0. Background questions (name, organization, position etc.)

[Questions about the Market related success factors]

\section{A. MP methods used}

1. Did you have any descripted and/or documented product development process in use?

2. In the beginning of the development process, did you try to find appropriate customers for your technology?

3. In the beginning of the development process, did you contact the customer in some way? For example, did you introduce the product to him/her?

4. Did you keep the customer in the loop during the development process? 5. Did the marketing sector (person or organization) belong to the development team?

\section{B. Focus on customer needs}

6. In the beginning of the development process, did you segment your appropriate customers?

7. In the beginning of the development process, did you try to define the exact need(s) of the customer/customer segments?

8 . How did you document customer related findings?

9. Did you interpret findings somehow?

10. Did you order/weight the needs somehow (e.g., importance)?

11. Did you update customer need (list) during the development process?

\section{Market development}

12. In the beginning of the development process, did you define the target market (existing/new)?

13. In the beginning of the development process, did you define the target market by some other more specific way?

14. Did you update/redefine the target market during the development process?

\section{Alternative study}

15. In the beginning of the development process, did you make an alternative study?

16. Did you notice the other solutions for customer needs than direct competitors (e.g., other indirect/potential technologies etc.)? 17. Did you update the alternative study during the development process?

\section{E. Adoption time/technophobia}

18. During the development process, how did you prepare yourself for customer adoption time in advance?

19. How did you take into consideration customer adoption time? How did you try to shorten it?

20. During the development process, did you take into consideration the customer's feeling about the usefulness of the product? How? 21. During the development process, did you take the ease of use into consideration? How?

[Questions about the Product related success factors]

\section{F. TP for difficult adopted}

22. How did the management prepare the project for the adoption time? 23. How was the commitment of management shown?

24. How was resource ensuring organized?

\section{G. Lifecycle}

25. How was the product's life cycle taken into consideration during the development process?

26. Was there any kind of economic planning for the life cycle period in the development phase?

27. Was there human resource planning for the life cycle period in development phase?

\section{H. Technological advantages}

28 . How do you see the technological ability of your project to develop as a breakthrough product?

29. How would you describe the technological advantage of your development team?

30. What technological advantages does your product have as compared to competitors or other available solutions?

[Questions about the Management related success factors]

\section{Management support}

31. What was the most important support from the firm's management for your project?

32. Did you have the needed financial and human resources for your project?

\section{J. Degree of funding}

33. Was the degree of funding (e.g., the agreed percentage of the total budget) included in the firm's strategy? How much was that share? 34. Was the development project prioritized from an economic point of view? 35 . How was the project funding monitored during the development process?

[Questions about the Organization related success factors]

\section{K. Project team skills}

36. How would you describe the experience of the development team members?

37. Was any kind of team training arranged during the development process?

38. How would you describe the development team members' expertise and ability?

39. How would you describe the versatility of development team? Was the team cross-functional?

\section{Networking}

40. Did your project network with the other organizations (firms or public sector e.g., research institutes)?

41. If this was the case, why did you do that? What benefits were achieved?

42. How did your project find or justify the network partners?

\section{General question}

43. Can you mention any other than discussed success factors which has influenced your [current or previous] firms' products commercial success? 
